\title{
RFID Technology Adoption Rate in Warehousing: A Study of Manufacturing Companies in Johor
}

\author{
Law Chong Seng1, Dr. Lim Kim Yew ${ }^{2}$ \\ ${ }^{1}$ Faculty of Business and Management, Southern University College, Malaysia \\ ${ }^{2}$ Faculty of Business Communications \& Law, INTI International University, Malaysia
}

\begin{abstract}
How to cite this paper: Law Chong Seng | Dr. Lim Kim Yew "RFID Technology Adoption Rate in Warehousing: A Study of Manufacturing Companies in Johor" Published in International Journal of Trend in Scientific Research and Development (ijtsrd), ISSN: 24566470, Volume-3 | Issue-3, April 2019, pp.144-153, URL: http://www.ijtsrd.co $\mathrm{m} /$ papers/ijtsrd216 81.pdf

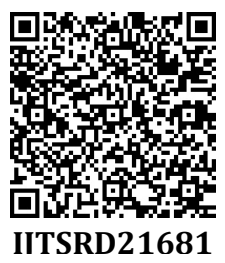

Copyright (C) 2019 by author(s) and International Journal of Trend in Scientific Research and Development Journal. This is an Open Access article distributed under the terms of the Creative Commons

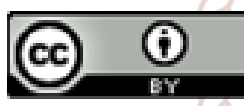
Attribution License (CC BY 4.0) (http://creativecommons.org/licenses/ by/4.0)

\section{INTRODUCTION}

Supply chains dependably require information about the properties of products or different elements engaged with operational procedures. A compelling and efficient information tracking and tracing system empowers a decision maker or an automated system to quickly react to lessen operational expense and increase efficiency [2]. Radio frequency identification (RFID) is a technology innovation that can significantly expand organizations' abilities to secure data about substances and their areas continuously [5].

RFID technology can be executed in various settings. For instance, RFID can be utilized inside a solitary firm to track and follow their costly resources and improve resource asset management [5]. RFID can be connected in tracking animals to enhance the domesticated animals' esteem. RFID is likewise used to accelerate tolling administration. Nonetheless, the most encouraging area for RFID technology innovation is supply chain management (SCM). RFID can be used in SCM from extremely regular activities, for example, moving products through loading docks, to complex ones, for example, overseeing continuously data around many merchandises on hand. RFID has the guarantee to help recognize container, pallet, case and things being manufactured, dispatched and sold along supply chains, give customers the correct item at the right place at the right time, and subsequently increase sales and benefits for all aspects of supply chain. RFID application for SCM can be found in the parts of coordination, retail, healthcare, automotive and textile [4].

Reducing costs while improving profitability and consumer loyalty is the objective of each supply chain, and it is one of the difficulties looking by administrators regularly. Numerous organizations, particularly those with highvolume pick, pack, and ship necessities, have put resources into material handling equipment (MHE), actualized warehouse management system (WMS) and Enterprise Resource Planning (ERP) systems to drive cost reduction and improve operational efficiency. While these progressions have yielded various advantages, organizations are yet hoping to accomplish more reserve funds and efficiency [28].

Overseeing warehouse activities today necessitates that you accomplish more with less. The management is requesting cost reductions year-over-year in labour, delivering, and space, with consistent improvement in productivity, throughput, and inventory accuracy. Customers are requesting consistence, value-added services, and shorter delivery lead times. Company must deliver these cost challenges to stay competitive [24]. 
As a feature of the arrangement, companies are utilizing a blend of automated equipment and software. Material handling with automation, for example, conveyors, sorters, carousels, AS/RS, RF, Pick-to-Light, and different advances have empowered numerous companies to build throughput, lessen work expenses, and diminishing order lead times. It is required high support cost and handy laborers to accomplish such execution [17].

As per Reyes (2011), just 20 to 30 percent of warehouse operations are considered efficient, and as investment in hardware goes up, system effectiveness goes down. The issue is that while material handling equipment and WMS/ERP software systems can freely convey extensive advantages, they are regularly helpless to discuss viably with one another, prompting wasteful aspects.

Warehouse is a fundamental segment in the supply chain, connecting the chain partners and furnishing them with elements of product storage, inbound and outbound activities alongside value-added services. Allocation of warehouse assets ought to be efficient and viable to accomplish higher productivity and diminish operational expenses. Radio frequency identification (RFID) is a technology innovation equipped for giving ongoing information about supply chain activities [24]. It has been utilized by warehousing and strategic undertakings to accomplish diminished shrinkage, improved material handling and tracking just as expanded accuracy of information accumulation. Absence of return on investment (ROI) and surprising expenses are the most normally detailed obstructions [17].

RFID is generally contrasted with another scanning technology such as barcode, the normally utilized for identification technology. In any case, RFID technology can give considerably more valuable information than standardized identification, for example, item distinguishing product number, price and cost, manufacture date, location, stock on hand, and so forth [9]. RFID can help to increase efficiency, exactness, and perceivability of supply chains activities, which thus lead to numerous advantages, for example, lower work costs, shorter process duration, lower inventory and improved customer administration [19].

The developing of literature on RFID keeps on giving important bits of knowledge to numerous RFID themes, for example, RFID adoption and effect on business operations. In most studies, however, examine RFID from a contextual analysis way to deal with concentrate explicit cases in which this technology is utilized or could be utilized to make an incentive for the businesses. A few studies address RFID diffusion from a customer's point of view, concentrating on protection and security issues. The adoption of RFID in supply chain is a complex process because of the component of the technology and the connections of technology adoption choices among the supply chain partners [30]. RFID adoption in one organization inside a supply chain may have impacts on whatever remains of the supply chain, so the adoption and mixture choices should be tended to in a progressively attentive way [40]. Furthermore, inquire about discoveries on RFID adoption have stayed divided and do not give a far-reaching comprehension of this phenomenon in supply chains [42].

From practitioner point of view, organizations and businesses which have been thinking about RFID adoption, execution, and use are keen on recognizing what precursors are basic to rouse RFID adoption and how RFID creates an incentive for organizations [36]. Then again, organizations which have been engaged with creating, institutionalizing and coordinating RFID technology are anxious to realize which factors they can feature to their customers so as to advance RFID adoption and use in supply chain applications. The absence of clever responses to the above issues represents a test for researchers and managers in IS field given that RFID is such a promising technology innovation for SCM. A lacking comprehension of RFID diffusion and esteem value will result in botched business chances as well as lead to wasteful business activities [25].

To pick up coordination benefits by this technology innovation, organizations who have adopted the technology early ought to stimulate their business partners to likewise embrace it early because such advances cannot be utilized singularly [35]. Potential adopters will observe the individuals who have taken on the technology before them to reduce uncertainties. When they have adopted the technology, they can influence the other potential adopters. The adoption of advancements in the system happens through the learning procedure by information and knowledge exchange by the implanted organizations [5]. Therefore, potential adopters are impacted by earlier adopters inside a system, and the dimension of impact by earlier adopters might be diverse as per their situations in a system just as their very own authoritative variables. These reasons may prompt distinctive appropriation timing on the diffusion process of technology innovation [30].

\section{PROBLEM STATEMENT}

There are gaps recognized in the current RFID literature. Gaps are absence of a hypothetical views for RFID adoption and infusion in supply chains. Lack of comprehension of critical success factors for RFID adoption. Lack of empirical assessment of RFID diffusion with huge example information, and lack of research that can assist experts with using RFID technology in SCM, just as to harden the measurement of RFID benefits for supply chain gains. In addition, in view of the special characteristics of RFID, organizations face a progression of hindrances in adopting and utilizing RFID to overcome critical technical, administrative and monetary issues [33], particularly identified with supply chain issues and technology development status for RFID diffusion studies. In some industry reports and white papers, the advancement status of RFID is frequently referenced as a noteworthy worry for current RFID adoption. In any case, the development status of RFID has not been researched widely in academic literature.

There are issues confronting the management of organizations in acceptance and usage of radio frequency ID (RFID) to improve supply chain management. For different reasons, organizations are hesitant to adopt RFID as a piece of their internal systems. There are uncertainties towards the selection which is uncertainties to the prerequisites and capacities of the technology itself and uncertainties with respect with the impacts of the technology on interorganizational connections [10]. Other than RFID gives numerous preferences towards organizations, it has additionally a few challenges. The usage of the technology into the current Information Technology (IT) system acquires immense technical difficulties [34]. The much increasingly considerable hierarchical changes required by 
the adoption of RFID, for example, the adjustments in the business processes and organizational structure [44]. RFID, by its nature, connects a wide area of the organization. This implies for organizations to completely reap the benefits of RFID, they should include different capacities, along these lines making a multi divisional condition [5].

Huge advancement is being made on the business utilization of the technology that make the whole industry supply chain visible, efficient, and functional oriented. Nonetheless, a few difficulties and barriers to a wide execution of RFID still exist. Uncertainty assumes a role in the adoption process, people would prefer not to be the first to utilize an unproven technology [25]. The observation that RFID is a complex innovation and require exertion of the entire organization, changing the hierarchical structure to a multidisciplinary level can give a few limitations towards the technology [44].

\section{RATIONALE OF THE STUDY}

RFID was introduced and used in the Malaysian environment at least 30 years ago. However, its use is considered still at initial or basic stage. Among the main reasons for this are costs, extent of availability of network infrastructure, lack of awareness of the technology advances aside from specialized use and status of standards development only of late. Other main issues contemplated are the real need of RFID technology implementation at any organization and the value that can be derived from it. Malaysian technology entrepreneurs have not been sitting still. Many are involved in implementing RFID systems and solutions, while others are actively involved in research and development of RFID equipment and software. RFID technology has hitherto been far too expensive for commercial use until this new century, though it is still too costly to use them to tag every item in warehouse especially.

Many factories, where their products require multiple processes and where volume is generally high, it is required advance technology such as RFID to track the movement of products at various stages, identify the bottlenecks and assesses the efficiency of the supply chain activities, so they can improve the supply chain processes. Today, such applications are still not feasible in Malaysia yet due to the relatively low labour costs here [37]. There is need to study factors affecting RFID technology adoption in supply chain as to identify criteria as source of concern for implementation decision making, benefits and barriers. Such study scope covers the integration challenges between existing supply chain system and RFID technology. Discuss the existing solutions to technological, investment and performance RFID adoption barriers. Identified criteria when implementing the RFID technology is available used to help alleviate implementation problems. By illustrating the adoption and implementation challenges of RFID technology in the supply chain environment, this study is aims to help both academics and practitioners to focus on key areas constituting an obstacle to the technology adoption. As more studies will address these challenges, the realization of RFID adoption for warehouses will become a reality.

To gain a proper conclusion of the problem, three questions are formulated as below:

A. What are the criteria for an organization when deciding to adopt RFID technology?

B. What are the benefits of adopting RFID technology?

C. What are the barriers for RFID technology adoption?

\section{LITERATURE REVIEW}

RFID is another innovation for the adopting organizations. Adoption is expressed as an internally created or obtained devices, system, policy, program, process, product or service that is new to the adopting organization [44]. As Rogers (2003) contends, adoption is a choice to make full utilization of innovation as the best strategy accessible. The adoption of innovation makes changes in the structure and working of an organization [36]. The adoption of innovation is imagined, include the generation development, and usage of new thoughts or practices [9]. The adoption of innovation is commonly proposed to add to the execution or adequacy of the adopting organization. Innovation is a method for changing an organization, regardless of whether as a reaction to change in its inward or outer condition, or as a pre-emptive move made to impact an environment. At the point when new technological innovations are presented, and particularly the information technology, they change the community [41].

\section{Benefits of RFID Technology Adoption}

\section{A. Improved Operation Processes}

The most bleeding edge technology for supply chain integrity and traceability is the RFID system [3]. Ongoing advances in RFID have empowered its initial adoption in numerous business applications, for example, supply chain management, logistics, and transportation. RFID technology is a supporting tool for automating processes and improving activities management in operations. The truth of the matter is that it can convey more capacity to the decision-making group by giving on time information. This modern technology adoption in warehouse is progressively valuable to the administration for at least one of the accompanying facts such as better supply chain and inventory management, reducing falsifying and misrepresentation controlling, tracking work-in progress, reducing managerial mistakes, reducing rework, better management of warranty claims, capable of working in reasonable and critical environments, better supply chain efficiency, cost saving and profit improvement.

Far reaching adoption of RFID offers alluring ways to lessen cost through more noteworthy coordination between marketing and manufacturing crosswise over supply chains [13]. For example, RFID could improve supply chain efficiency through ongoing tracking, safety checking, and by and large warehouse activities, which prompts increments in sales volumes and improving profitability for suppliers and retailers [19]. The extent of the advantage relies upon the dimension of tagging pallet, case, item and the area of use in the warehouse.

\section{B. Reduce Operating Costs}

Manufacturers can utilize RFID solutions to lessen operating expenses through diminishing the labour costs, claims, and returns [28]. This will assist them with increasing the operating income. They likewise can diminish the working capital by empowering decreases in inventory and bringing down the inventory write-off from the return products and those things that are unsaleable toward the end. Fundamental advantages of RFID can be ordered as to improve the speed and accuracy for tracking pallets, cartons, and containers, helping to decrease stock levels, helping to decrease working expenses, improving the management of inventory, improving efficiencies in work in process reporting, and improving inventory visibility to support just in time systems. 


\section{Automatic Identification}

Rising as a standout amongst the most unavoidable technologies at any point created, RFID technology is picking up prominence as a technology of automatic identification [35]. By enabling warehouse to track physical assets and keep up information about items consistently, RFID technology considers total information integration with the supply chain [34]. In this sense, RFID innovation addresses the focused organization's issue to detect and react through integration of IT infrastructure [8]. RFID works by enabling a reader to read and write to a remote transponder (additionally called a tag) through electromagnetic waves [2]. In this sense, RFID enhances barcode scanning by taking into consideration the distinguishing items without observable pathway being vital between the reader and the tag [8].

\section{Improved Business Plan}

Companies use RFID technology for the most part for three purposes: to lessen cost, to all the more likely serve customers, and to help business development through for instance expanding market share [22]. Generally, most of RFID technology extends in organizations expressly or certainly address one or a few of these goals. As per Bunduchi et al (2011), in pretty much every case, RFID presentation can be viewed as an ICT-empowered process innovation. Understanding one's business forms and having a clear vision how they could be saved costs or to improve service quality, are in this way basic prerequisites for firms to successfully utilize RFID technology. The expanding competitive pressure on organizations, a significant number of them working in a worldwide economy, has been a solid driver for ICT adoption in general and RFID technology specifically.

\section{E. Reduced Shrinkage}

Shrinkage is defined as stock loss which leads to inventory accuracy. Shrinkage can be caused by a variety of reasons. However, the most common cause is theft. Other sources of shrinkage can be administrative errors, misplacement, spoilage damaged products or vendor fraud. According to Osyk et al. (2012), RFID could reduce the occurrence of shrinkage in these areas. The annual cost of shrinkage in the United States only has been estimated on $\$ 30$ billion a year. Fleish and Tellkamp (2005) reported that shrinkage accounted for $2 \%$ to $4 \%$ of sales in the US industry in 2001 . Along the same line Alexander et al. (2002) found that the amount of inventory shrinkage rate is around $1.75 \%$ of 2001 sales in the US, Europe, Australia and Asia. ECR Europe (2003) reported that in Europe the shrinkage rates were $0.56 \%$ for manufacturers. Twist (2005) estimates that RFID can reduce this amount by two-thirds. Lee and Ozer (2007) researched the difference in shrinkage before and after the implementation of RFID technology, they report that between $10 \%$ and $66 \%$ of the original shrinkage observed is reduced after the implementation of RFID technology.

\section{F. Increased Data Accuracy}

Inaccuracy of inventory is serious issue for any industry [38]. Kang and Gershwin (2005) found in their research that the best performing store in their example just had 70-75\% of its inventory record coordinated with the actual inventory. The average accuracy of inventory in the study of Kang and Gershwin (2005) was 51\%. RFID could improve inventory records by lessening human mistakes in material handling [38]. RFID could likewise build the exactness of the shipment data, which could improve demand forecast and production planning. Moreover, RFID could expand the exactness of inventory records [38], the expanded data accuracy can possibly improve the quality of the management decisions since the management presently has accurate data to base on their decisions. Moreover, Tajima (2007) states that RFID usage introduces a chance to review cleanse and synchronize business data, for example, product catalogues and supplier information. Clearly, RFID can possibly build the data accuracy within an organization, prompting the advantages referenced previously. Hence expanded data accuracy could be criteria for organizations to adopt RFID.

\section{G. Improved Information Sharing}

When organizations are collaborative, RFID increases the sharing of data in the supply chain among the organization in this chain [38]. Information on the RFID tags can be read and updated in real time while they move through the supply chain. The tags can have more information for the supply chain partners, improving the information sharing [42]. Consequently, this automation would reduce the manual tracking of paper trails. Moreover, access to detailed supply chain data would enable RFID to offer flexible information sharing by customising the level of aggregation of supply chain data [23]. The increased synchronisation through the sharing of information enables organizations to start with collaborative, forecasting, planning, and replenishment (CFPR) activities which go beyond the classic buyer seller relationship [42]. RFID can function as an enabler for improved information sharing for organizations in a collaborative supply chain, which could lead to CFPR and a close buyer seller relationship. This might be a decisive factor for an organization to adopt RFID.

\section{H. Reduced Material Handling}

Numerous benefits of RFID relate to the reduction of material handling and inspection time [38]. Quirk and Borello (2005) estimate that RFID results in a $40 \%$ decrease in inventory counting time. RFID can also decrease human errors in labour intensive and error-prone operations like data entry and counting [32] and can decrease location errors with $90 \%$ [27]. The impact is the most significant for warehouse operations since $50-80 \%$ of the labour cost are related to material handling. RFID enables the scanning of multiple items at the same time which reduces time spent on dealing with receiving goods consequently resulting in costs savings and higher profitability [42]. Other benefits specifically for warehouse operations include automated routing for cross-docking, fewer shipping delays, shorter delivery lead times, and quicker customs clearance for crossborder shipments. As a result, reduced material handling leads to lower labour cost and increased productivity which could be a reason for an organization to adopt RFID.

\section{Increased Supply Chain Visibility}

RFID has the potential to increase the visibility of the supply chain. It facilitates the possibility of making information visible to all the supply chain partners [2]. Increased data accuracy, increased information sharing among the supply chain partners and the ability to track and trace the movement of goods throughout the supply chain enabled by RFID increases the visibility of the supply chain [2]. Due to increased supply chain visibility the partners in the supply chain always have up to date and accurate information which they can use for their own advantage [38]. It could for 
instance enable paperless invoicing [32] and ease the distribution processes like receiving and checking-in goods, put away and replenishment of goods, order filling and shipping [2]. All things considered increased supply chain visibility could be an important factor for an organization to adopt RFID.

\section{Barriers of RFID Technology Adoption A. Uncertainty of Technology}

Through the moderately newness and complexity, RFID technology involves the market a few uncertainties, which keeps down adoption of this technology. The originality of a thought gives the dispersion its unique character it makes uncertainty inside the process. Diffusion is characterized as the process in which an innovation is imparted through specific channels after some time among the individuals from a social system [30]. While uncertainty is how much various choices are seen regarding the event of an occasion and the general likelihood of these choices. Uncertainty is impacting adoption rate, it prevails the true value of the technologies [9]. The idea of the uncertainty is with the end goal that the estimations of the technologies can be learned just by really utilizing them [19]. Organizations may see the reasonability of adopting a specific innovation. Set up together, singular technology adoption and organizational dimension technology adoption, represent to an abundance of information with respect to the innovation adoption process. These hypotheses give evidence that an assortment of factors impact whether potential adopters will accept or reject new technology inside a social system [6].

\section{B. Lack of Awareness}

Factors that restraining RFID technology adoption like lack of awareness that leads to ROI uncertainty; due to the lack of awareness and in-depth understanding of RFID system such as the needs required to use captured data to improve the existing warehouse transactions. The clarity on total cost of ownership issues among various parties which include system integrators, middleware software developers, tag and reader manufacturers makes the cost of ownership become an issue as to which party should absorb certain costs related to RFID implementation and related development along the value chain [15].

\section{Lack of ROI and High Cost of Investment}

Accomplishing a positive ROI on RFID technology usage in the warehouse of supply chain keeps on being a test for some organizations. The cost of high technology is yet they represent the moment of truth issue for some organizations and their customers [9]. An essential cost part of RFID technology is the repetitive cost of RFID tags. Furthermore, organizations considering RFID technology need to get ready for extra system infrastructure, storage capacity, RFID printers and readers, and extra data produced by a great many new tags streaming in its supply chain [3].

The circumstances for using RFID technology do not generally make a straightforward undertaking. Singular tags right now run from US\$ 0.25 - 0.35 per unit. In this way, essential applications for RFID systems have been constrained to cases where the cost of the tag is not an issue [29]. Just $30 \%$ of Wal-Mart's suppliers had the ability to execute the RFID project in 2005 [29]. Adding to the multifaceted nature, the models of RFID are not yet completely established. These elements will probably obstruct businesses as they move to adopt and actualize RFID technology.
Roberti (2007) proposes that the reasons that RFID did not accomplish an expansive scale adoption in the retail and consumer bundled merchandise supply chain in 2006 were because of factors, for example, the cost of tags, and the ROI of RFID adoption. Angeles (2005) articulates that the rules for IT and business managers to proactively execute RFID technology in the principal organize make the ROI cases for the moderate development of RFID. Managers, consequently, face a situation in which the commitment of RFID technology to take a stab at the upper hands is hollowed against uncertainties as to its actual business value. This has prompted a reasonable need to track the accomplishment of RFID investments. There is a conspicuous requirement for an apparatus which is sufficiently straightforward for simple management adoption, adequately ground-breaking for diagnosing these areas of shortcoming, and simple enough to encourage the feedback fundamental for persistent rearrangement and improvement processes.

\section{Integration Issues}

There is a need to share experiences to understand the more complex integration issues that would require some degree of re-engineering in business process. In short, issues on standardisation amongst various protocols between RFID systems, back-end systems and middleware need to be worked out within the localised context of use in RFID adoption [35]. Privacy and security concerns, these issues have been raised by users due to the RFID capability today of providing wider tracking and tracing approach that could potentially invade (be it intentionally or unintentionally) an individual's privacy and impose a violation of confidentiality and security of communications network [33]. In accuracy concerns, read rate accuracy is a concern owing to the electromagnetic field used for communication between the reader and the tags especially in close-proximity [39]. Also, the type of tags, tag design, and the orientation of the tag need to be taken into consideration as well.

\section{E. Business Challenges}

There are several business-related challenges that stand in the way of wide-spread RFID adoption [5]. Effective RFID implementation and use in a multi-firm context that requires inter organizational cooperation among a network of firm involved in implementing RFID technology is likely to face project-management challenges as individual firms with their own specific objectives for RFID adoption may differ and conflict [5]. Another challenge project-management face is the integration of RFID technology and legacy systems [3]. Since RFID technology is still developing no packaged solutions for RFID technology are available, given that most organizations have a unique process model which brings additional project-management challenges [3]. Organizations must find techniques to make RFID data interface with related business applications such as accounts receivable, inventory management, etc on their own [2]. Hart and Saunders (1998) studied the role of trust in the adoption and use of Inter Organizational System (IOS) and found that trust is a critical factor influencing the use of IOS. Yang and Jarvenpaa (2005) state that organizations adopting an IOS like RFID within an alliance in which associated organizations have comparative power collective trust among these organizations is critical for the successful adoption of RFID. Implementing RFID also requires integration with the current systems of an organization. Furthermore, acquiring the specialized skills required for RFID implementation and operation might be difficult since 
few employees are experienced in RFID implementation [3]. Moreover, organizations will need employees who can easily integrate technical and business challenges, such integrative personnel are hard to find and train [3]. Integration challenges like high costs, lack of specialized skills and personnel can stand in the way of RFID adoption.

\section{F. Popularity of Bar Codes}

The popularity of bar codes is also a barrier for large scale RFID adoption, almost all industry around the world use bar codes. Every year 5-10 trillion bar codes are printed and about 5 billion bar code scans are performed daily entrenching it deeply into the operations of organizations [38]. Twist (2005) argues that bar codes are cheap, standardised and already achieving a satisfactory performance level. So even though RFID has a lot of benefits over barcodes, barcodes are deeply entrenched in the daily operation which is not helping large scale RFID adoption [15].

\section{Previous Researches and Findings}

There are couple of techniques accessible to consider and comprehend the RFID technology adoption. The technology acceptance model (TAM) is an outstanding and often applied user acceptance show in the study of IS and has been connected to a different set of technologies and users [41]. Innovation diffusion theory (IDT) gives another model that can be utilized while presenting another IT or innovation into an organization. This theory was at first created by Rogers in 1985 to delineate the innovation-decision process in large organizations. The model gives a suitable framework to studying IT innovation diffusion. IDT has been generally used to anticipate and clarify the adoption of technology in different domains.

Zmud (1984) recommends utilizing the technology push (TP) and need-pull (NP) concepts to clarify conduct in the adoption of new technology. Shih et al. (2008) utilize the TP/NP concept to look at the adoption of a RFID system in Taiwan. While research uncovered various functions that fundamentally influence RFID technology adoption, one of the key discoveries is that presenting new technology is not always independent of existing organization structures and processes. According to Asif and Mandviwalla (2005), an organization that is strategically innovative in its utilization of RFID adoption technology, utilizing, for instance, electronic data interchange (EDI) to streamline its document processing, is generally readier to adopt a technology such as RFID.

Mabert et al. (2003) studied that organizational size is the most as often as possible examined basic variable and has been utilized to consider issues identifying with innovation, R\&D expenditures and market control. Goode and Gregor (2009) likewise see organizational size as imperative in the analysis of organizations and technology. Regardless of the prominence and evident significance of organizational size for the study of IS, the measure of theoretical and empirical work managing the connection of firm size and RFID utilization is small.

Among Australian SMEs, Huber et al. (2007) found a highperceived business value of RFID adoption contrasted with other e-Business instruments, for example, electronic proof of delivery and electronic reports. Be that as it may, the small size of their interview sample must be contemplated, which lessens the significance of any statement about the general significance of RFID for SMEs. The incorporation of exclusively SMEs does not consider any ends with respect to orderly contrasts among SMEs and LEs. This limitation additionally applies to Zhang et al. (2008) who studied the deployment of RFID tracking alternatives in two British SMEs.

Martilla and James (1977) first proposed IPA as a tool to build up firms' management techniques. IPA has kept on being a mainstream the management tool among researchers in the areas of service quality, travel and the tourism industry, leisure and entertainment, education, healthcare, new product success, and diagnosing IS success. IPA is a lattice-based method that joins the proportions of quality significance and execution into a two-dimensional grid [21]. IPA starts with the generation of a set of key attributes of an objective item and afterward ranks each attribute for its significance as far as of a purchasing decision. These attributes, which are basic for analysis, are for the most part gotten from literature or interviews from which survey instruments are created. At long last, the significance and execution of the recognized components are plotted against one another, considering for correlations to be made.

\section{THEORETICAL FRAMEWORK}

This study analyses the use of RFID by companies in Johor which are actively involved in the warehouse activities and management, in manufacturing sector based on the three research questions as discussed in research question. The study provides a top-down view of RFID adoption rate and challenges, starting from the overall picture at Johor. It also illustrates adoption patterns and drivers across the various sectors addressed, with a focus on benefits, barriers and opportunities. The topic is utterly relevant, as RFID technology adoption is a major driver for the improvement of efficiency and effectiveness of business processes. Fig.1 shows the dependent variable: adoption rate of RFID technology and independent variables: technology, organization and environment. The factors are grouped within the categories as mentioned in the research framework.

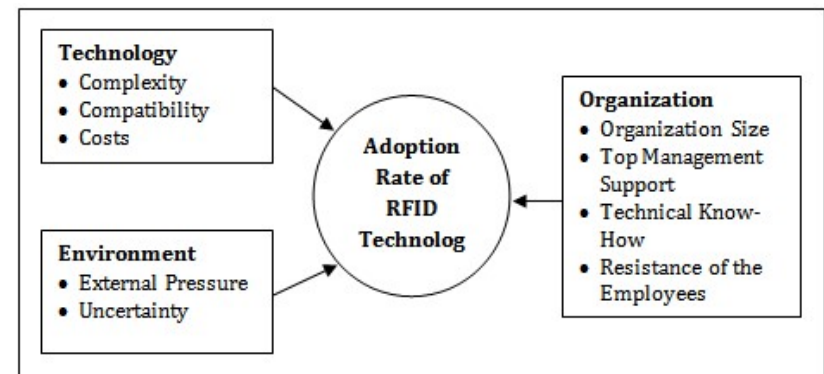

Fig. 1: Theoretical framework of adoption rate of RFID technology

\section{Technological Factors}

The multifaceted nature of an innovation is a vital factor with respect to the choice to adopt a new technology. The level of unpredictability demonstrates that it is so hard to comprehend, execute, and to utilize the innovation or new technology [30]. The higher the complexity of an innovation the higher are the questions regarding the likelihood of an effective implementation within an organization. Subsequently, if the technology is seen as too complex 
organizations could defer the adoption of RFID [39]. Compatibility has been appeared critical factor in innovation literature to clarify the use of a new technology by organizations [46]. As indicated by Rogers (2003), compatibility is characterized as how much RFID is compatible with the organization's business processes, IT systems, distribution channels, corporate culture and value system. Thusly, the higher the compatibility of a technology is the higher is the opportunity of an adoption. Tornatzky and Klein (1982) could demonstrate that costs are an inhibitor of technology use. Earlier IT and EDI adoption studies could likewise validate this connection.

\section{Organizational Factors}

The size of an organization has been reliably perceived as a quickening agent for the adoption of innovations. Large organizations will in general have more prominent financial resources which are important to test, pilot, and after that to choose whether to adopt RFID technology. They are bound to accomplish economies of scale and are progressively equipped for bearing high risk related with beginning stage investment. Moreover, they often have more capacity to mandate supply chain partners to adopt an innovation with system externalities [20].

The support of the top management of an organization has been appeared to be another essential IT adoption indicator. Particularly for RFID, as a network technology, where key advantages might be acknowledged through improved partner coordination, higher transparency, and the requirement for new processes, signals should be conveyed within an organization and the supply chain about the significance of the adoption of RFID technology and the commitment of the top management [5].

The factor technical know-how portrays the current knowledge within an organization [36]. Organizations that as of now have the knowledge about a technology can be more likely assess the advantages, drawbacks, costs, and requirements that must be considered for an adoption. Organizations without technological know-how perhaps see the innovation as excessively complex. Besides, organizations with more knowledge about the technological innovation are bound to execute a forceful technology adoption strategy [30].

Employees who believe that they do not have the essential capability for the control and activity of a new technology may fear the loss of their jobs. Because of these stresses they could think of an exceptional obstruction with respect to the execution [41]. Particularly if there should arise an occurrence of the RFID technology which most likely will substitute manual scanning processes those resistances have to be expected.

\section{Environmental Factors}

External pressure can impact the decision making of an association regarding the adoption of a new technology. Examples are governmental influences, the competitive environment or commands given by supply chain partners [30]. Uncertainty starts from a lack of information, knowhow, or the failure to foresee developments and circumstances [30]. Organizations are regularly questionable regarding the interest for their products, the loyalty of their customers or general developments in the market environment.

\section{RESEARCH METHODOLOGY}

This study used random sampling method as it involved all types of manufacturing companies in Johor. The company decision making criteria, system development desire, consideration, benefits and problems, all are taking into consideration to obtain sufficient samples for research purpose. Throughout the 150-questionnaire distributed to manufacturing companies, there were 98 companies reply with complete answers. With all required information and data available after identified the dependent and independent variables, defined the target population and the survey method was selected, SPSS software used to carry out the data analysis. Types of data analysis were adopting percentage, cross tabulation, and correlation test.

\section{RESEARCH FINDINGS}

There were total of 98 respondents in the survey which were consists of $68.4 \%$ male and $31.6 \%$ female. Most of the respondents were from the age of 31 to 42 and it is $65.3 \%$. Majority of respondents are working as Manager and Senior Manager in their company, and it is $70.5 \%$. Electrical/electronic industry and plastic injection moulding industry were having most companies participated in the survey, and it is $42.9 \%$ in total. The survey also shows $84.7 \%$ of companies were adopting RFID technology and $15.3 \%$ of companies are yet to have implementation.

The survey also shows companies have yet to adopt RFID technology in warehouse may have future implementation plan. There were $6.7 \%$ will implement it within one year, $40 \%$ will implement it within one to six years. $13.3 \%$ will only implement it after six years. Even most of the companies have implementation plan, there were $40.0 \%$ have no plan at all. With further survey, researcher also collected data from respondents to understand their knowledge in RFID technology. Most of the companies understand most of the concepts of RFID, and it is $54.3 \%$.

\section{What are the Criteria for an Organization When Deciding to Adopt RFID Technology in Warehouse?}

The criteria for an organization when deciding to adopt RFID technology in warehouse in the survey are size of company, technical know-how, type and flow of system, investment costs, staff competencies, products and customer requirements, and top management support. Derived from the data analysis and findings, respondents were fully accepted criteria of technical know-how, investment costs, staff competencies, products and customer requirements, and top management support. $63.1 \%$ of respondents were accepted size of company as criteria, while $99 \%$ of respondents were accepted type and flow of system as criteria. There were $71.4 \%$ respondents from chemical industry accepted size of company as criteria, $91.7 \%$ from food industry, $81.9 \%$ from metal stamping industry, and other industries. $85.7 \%$ respondents from chemical industry were strongly accepted investment cost as criteria, while $50 \%$ in electrical/electronic industry. $60 \%$ of respondents from industrial engineering industry accepted top management support as criteria, while $58.3 \%$ in electronic/electronic industry, and other industries.

The study also shows respondents' knowledge towards RFID technology. $54.3 \%$ of respondents understand most of the concepts of RFID and $16.3 \%$ fully conversant with all aspects of RFID. By looking at the correlation results, it has significant moderate positive correlation with size of 
company criteria and significant moderate negative correlation with staff competencies criteria.

When an organization deciding for RFID technology adoption, technical know-how is significantly strong positive correlated with type of flow of system. Eventually a systematic flow in warehouse is required enough technical knowledge to manage RFID technology as well as cost of investment. Staffs must be trained and equipped with technology knowledge to operate RFID system to manage products and customer requirements. The support from top management is vital to allow the success of RFID technology adoption in warehouse. Criteria accepted by respondents for this study may not represent the actual situation in their companies as it was from their own expectation and experiences.

\section{What are the Benefits of Adopting RFID Technology in Warehouse?}

There were three areas explored the benefits of adopting RFID technology in warehouse: Inventory management improvement, warehouse operation enhancements, and warehouse operation cost reduction. From the inventory management improvement results, respondents were fully accepted benefits of improved inventory accuracy, inventory records up to date, reduce stock out and data collection in real-time, while $86.7 \%$ for avoid over stock in warehouse as benefits. By sector, $41.7 \%$ of respondents from plastic injection moulding industry were strongly accepted improved inventory accuracy as benefit, while $36.4 \%$ from food industry, and other industries. Inventory records up to date have significant positive correlation with reduce stock out and data collection in real-time. By implementing RFID system in warehouse, it allows data transfer to inventory system in real-time, thus records are up to date. Up to date inventory records helps to prevent out of stock and over stock. Real-time data collection would increase inventory accuracy as inventory records are properly managed and planned.

In warehouse operation enhancements, respondents were fully accepted improved operation processes, reduce operating costs and material handling, and automatic goods identification, while $86.8 \%$ for reduce shrinkage in warehouse as benefits. By sector, $63.6 \%$ of respondents from food industry were strongly accepted improved operation processes as benefit, while $50.0 \%$ from IT/computer parts industry, and other industries. Reduce operating costs have significant positive correlation reduce material handling and reduce shrinkage. Reduce material handling means reduce in manpower and equipment handling, ultimately reduce operating costs as well as preventing stock lost and misplaced in warehouse.

In warehouse operation costs reduction, respondents were fully accepted reduced distribution costs as benefit. 79.5\% accepted reduced staffing costs, as well as reduced administrative expenses, and $90.4 \%$ accepted minimized over shelf life product as benefits. By sector, respondents from machinery industry were fully accepted reduced administrative expenses as benefit, while $91.6 \%$ from plastic injection moulding industry, $83.3 \%$ from chemical industry, and other industries. Reduced staffing costs have significant positive correlation with reduced distribution costs. Reduce manpower in warehouse by using RFID technology as alternative would help in cost reduction in goods distribution because of potential lower overhead cost. When over shelf life product is minimized, it reduces administrative expenses such as stock take cost, re-order cost, space utilization cost, scrap cost and other costs.

\section{What are the Barriers for RFID Technology Adoption in Warehouse?}

Respondents have selected implementation cost as key barrier for RFID technology adoption in warehouse. There were $47.1 \%$ responses. As for the problems considered when decide for adopting RFID technology, respondents fully accepted uncertainty of ROI, lack of skilled workforce, and insufficient market acceptance, while $92.9 \%$ for lack of awareness, $94.1 \%$ for uncertainty of technology, $72.9 \%$ for no business benefits, and $85.9 \%$ for bar code is more convenient as problems considered. By sector, $66.7 \%$ respondents from chemical industry, $42.9 \%$ from machinery industry, and other industries.

Lack of RFID technology awareness has significant positive correlation with uncertainty of technology and uncertainty of ROI. Most of the companies may lack of RFID technology awareness which could lead to uncertainty of technology that would help and benefited to warehouse operation. Top management may assume there is no business benefit for technology adoption. Lack of technology awareness may also lead to uncertainty of ROI. Companies' management may hesitate to put in substantial investment. Even the company implementing RFID technology, it should have skilled workforce to manage the advanced technology in warehouse. No doubt, the popularity of paper bar code label would be the major barrier, while insufficient market acceptance is the reason most of companies set back the implementation of RFID technology.

\section{CONCLUSION}

The comprehensive survey brought out the current situations, the RFID adoption rate, and the benefits and barriers of this technology in Johor's manufacturing companies. The manufacturing companies especially its warehouses may consider the findings of this study as a RFID implementation strategy. They may compare their experience with the findings of this study, evaluate the possibility, and find the future direction. Therefore, Malaysia government needs to justify its stand and work seriously on this technology distribution, and more open markets in general. This study considers that technological, organizational, and environmental factors remain constant. Furthermore, as the current application of RFID is far from its full application, future study may clarify the technology fulfillment and extended usage by the RFID adopters which will confirm the addition of potentials in the RFID adoption.

\section{REFERENCES}

[1] Alexander, K., T. Gilliam, K. Gramling, C. Grubelic, H. Kleinberger, S. Leng, D. Moogimane, C. Sheedy. 2002. Applying Auto-ID to Reduce Losses Associated with Shrink. IBM Business Consulting Services, MIT Auto-ID Center White Paper.

[2] Angeles, R. (2005). RFID Technologies: Supply-Chain Applications and Implementation Issues. Information Systems Management, 22(1), 51-65.

[3] Asif, Z., \& Mandviwalla, M. (2005). Integrating the Supply Chain with RFID: A Technical and Business 
International Journal of Trend in Scientific Research and Development (IJTSRD) @ www.ijtsrd.com eISSN: 2456-6470

Analysis. Communications of the Association for Information Systems, 15, 393-427.

[4] Attaran, M. (2007). RFID: An Enabler of Supply Chain Operations. Supply Chain Management: An International Journal, 12(4), 249-257.

[5] Barjis, J., \& Wamba, S. F. (2010). Organizational and Business Impacts of RFID Technology. Business Process Management Journal, 16(6), 897-903.

[6] Baskerville, R., \& Pries-Heje, J. (2001). A Multipletheory Analysis of a Diffusion of Information Technology Case. Information Systems Journal, 11(3), 181-212.

[7] Beck, A., Chapman, P. G., \& Peacock, C. (2003). Shrinkage: A Collaborative Approach to Reducing Stock Loss in the Supply Chain. Brussels: ECR Europe.

[8] Bose, I., \& Pal, R. (2005). Auto-ID: Managing Anything, Anywhere, Anytime in the Supply Chain. Communications of the ACM, 48(8), 100-106.

[9] Bunduchi, R., Weisshaar, C., \& Smart, A. U. (2011). Mapping the Benefits and Costs Associated with Process Innovation: The Case of RFID Adoption. Technovation, 31(9), 505-521.

[10] Cannon, A. R., Reyes, P. M., Frazier, G. V., \& Prater, E. L. (2008). RFID in the Contemporary Supply Chain: Multiple Perspectives on its Benefits and Risks. International Journal of Operations \& Production Management, 28(5), 433-454.

[11] Fleisch, E., \& Tellkamp, C. (2005). Inventory inaccuracy and supply chain performance: A simulation study of a retail supply chain. International Journal of Production Economics, 95(3), 373-385.

[12] Goode, S., \& Gregor, S. (2009). Rethinking Organizational Size in IS Research: Meaning, Measurement, and Redevelopment. European Journal of Information Systems, 18(4), 4-25.

[13] Günther, O., Kletti, W., \& Kubach, U. (2010). RFID in Manufacturing. Berlin: Springer.

[14] Hart, P., and Saunders, C. (1998). Emerging Electronic Partnerships: Antecedents and Dimensions of EDI Use from the Supplier's Perspective. Journal of Management Information Systems, 14(4), 87-111.

[15] Huber, N., Michael, K., \& Mccathie, L. (2007). Barriers to RFID Adoption in the Supply Chain. 2007 1st Annual RFID Eurasia, 1-6.

[16] Kang, Y., S.B. Gershwin. (2005). Information Inaccuracy in Inventory Systems - Stock Loss and Stockout. IIE Transactions, 37, 843-859.

[17] Karagiannaki, A., Papakiriakopoulos, D., \& Bardaki, C. (2011). Warehouse Contextual Factors Affecting the Impact of RFID. Industrial Management \& Data Systems, 111(5), 714-734.

[18] Lee, H. and Ozer, O. (2007). Unlocking the Value of RFID. Production and Operations Management, 16(1):40-64.

[19] Lin, C., \& Ho, Y. (2009). RFID Technology Adoption and Supply Chain Performance: An Empirical Study in Chinas Logistics Industry. Supply Chain Management: An International Journal, 14(5), 369-378.
[20] Mabert, V. A., Soni, A., \& Venkataramanan, M. A. (2003). The Impact of Organization Size on Enterprise Resource Planning (ERP) Implementations in the US Manufacturing Sector. Omega, 31(3), 235-246.

[21] Martilla, J. A., and James, J. C. (1977). ImportancePerformance Analysis. American Marketing Association, 41(1), 77-79.

[22] Mehrjerdi, Y. Z. (2011). RFID Adoption: A Systems Thinking Perspective Through Profitability Engagement. Assembly Automation, 31(2), 182-187.

[23] Murphy-Hoye, M., H. L. Lee and J. B. Rice, Jr. (2005). A Real-World Look at RFID. Supply Chain Management Review, 9(5), 18-24.

[24] Osyk, B. A., Vijayaraman, B., Srinivasan, M., \& Dey, A. (2012). RFID Adoption and Implementation in Warehousing. Management Research Review, 35(10), 904-926.

[25] Otondo, R. F., Pearson, A. W., Pearson, R. A., Shaw, J. C., \& Shim, J. P. (2009). Managerial Problem-solving in the Adoption of Radio Frequency Identification Technologies. European Journal of Information Systems, 18(6), 553-569.

[26] Papastathopoulou, P., Avlonitis, G. J., \& Panagopoulos, N. G. (2007). Intraorganizational Information and Communication Technology Diffusion: Implications for Industrial Sellers and Buyers. Industrial Marketing Management, 36(3), 322-336.

[27] Quirk, R.E., \& Borrello, S.J., (2005). RFID: Rapid Deployment and Regulatory Challenges. Venable LLP White Paper.

[28] Reyes, P. M. (2011). RFID in the Supply Chain. New York, NY: McGraw-Hill.

[29] 7 Roberti, M. (2007). Wal-Mart, suppliers affirm RFID benefits [online]. RFID Journal. Available from: http://www.rfidjournal.com/article/articleview/3059 /1/1/ [Accessed 12 May 2012].

[30] Rogers, E. M. (2003). Diffusion of Innovations (5th ed.). New York: Free Press.

[31] Roh, J. J., Kunnathur, A., \& Tarafdar, M. (2009). Classification of RFID Adoption: An Expected Benefits Approach. Information \& Management, 46(6), 357-363.

[32] Rutner, S., Waller, M.A., Mentzer, I.T. (2004). A Practical Look at RFID. Supply Chain Management Review, 8(1), 36-41.

[33] Shih, D., Chiu, Y., Chang, S., \& Yen, D. C. (2008). An Empirical Study of Factors Affecting RFIDs Adoption in Taiwan. Journal of Global Information Management, 16(2), 58-80.

[34] Spekman, R. E., \& Sweeney, P. J. (2006). RFID: From Concept to Implementation. International Journal of Physical Distribution \& Logistics Management, 36(10), 736-754.

[35] Srivastava, B. (2004). Radio Frequency ID Technology: The Next Revolution in SCM. Business Horizons, 47(6), 60-68.

[36] Strüker, J., \& Gille, D. (2010). RFID Adoption and the Role of Organisational Size. Business Process Management Journal, 16(6), 972-990. 
International Journal of Trend in Scientific Research and Development (IJTSRD) @ www.ijtsrd.com eISSN: 2456-6470

[37] Sulaiman, S., Umar, U. A., Tang, S., \& Fatchurrohman, N. (2012). Application of Radio Frequency Identification (RFID) in Manufacturing in Malaysia. Procedia Engineering, 50, 697-706.

[38] Tajima, M. (2007). Strategic Value of RFID in Supply Chain Management. Journal of Purchasing and Supply Management, 13(4), 261-273.

[39] Tornatzky, L.G., \& Klein, K. (1982). Innovation Characteristics and Innovation Adoption Implementation: A Meta-analysis of Findings. IEEE Transactions on Engineering Management, 29(1), 2845.

[40] Twist, D. C. (2005). The Impact of Radio Frequency Identification on Supply Chain Facilities. Journal of Facilities Management, 3(3), 226-239.

[41] Venkatesh, Morris, Davis, \& Davis. (2003). User Acceptance of Information Technology: Toward a Unified View. MIS Quarterly, 27(3), 425-478.
[42] Visich, J. K., Li, S., Khumawala, B. M., \& Reyes, P. M. (2009). Empirical Evidence of RFID Impacts on Supply Chain Performance. International Journal of Operations \& Production Management, 29(12), 1290-1315.

[43] Yang, G., Jarvenpaa, S.L. (2005). Trust and Radio Frequency Identification (RFID) Adoption within an Alliance. Proceedings of the 38th Hawaii International Conference on System Sciences (HICSS'05), Hawaii.

[44] Zaltman, G., Duncan, R., \& Holbek, J. (1984). Innovations \& Organizations. Malabar, FL: R.E. Krieger Pub.

[45] Zhang, J., Feng, P., Wu, Z., \& Yu, D. (2008). Automatic Identification-enabled Traceability in Supply Chain Management. In Proceedings of IEEE Xplore: International Conference on Wireless Communications, Networking and Mobile Computing.

[46] Zmud, R.W. (1984). An Examination of "Push-pull" Theory Applied to Process Innovation in Knowledge Work. Management Science, 30(6), 727-738. 